\title{
Evaluasi Penyuluhan Penggunaan Benih Unggul Padi Gogo Bersertifikat Terhadap Tingkat Pengetahuan Petani di Desa Nekan, Kecamatan Entikong, Kabupaten Sanggau (Perbatasan RI - Malaysia)
}

\author{
Rifqi Pasca Very Dwi Pani ${ }^{1 *}$ \\ ${ }^{1}$ Sekolah Pascasarjana, Penyuluhan dan komunikasi Pembangunan, Universitas Gadjah Mada \\ *Corresponding author: rifqipasca2020@mail.ugm.ac.id
}

\begin{abstract}
Abstrak
Tujuan dari penelitian ini adalah untuk mengevaluasi hasil penyuluhan penggunaan benih unggul padi gogo bersertifikat terhadap tingkat pengetahuan petani di Desa Nekan Kecamatan Entikong Kabupaten Sanggau. Pengumpulan data menggunakan pendekatan participatory rural appraisal (PRA) untuk menemukan masalah prioritas dan penyebaran kuesioner. Data kuisioner dirancang dan dianalisis untuk mengetahui tingkat pengetahuan petani terhadap penggunaan benih unggul padi gogo bersertifikat. Hasil penelitian menunjukkan bahwa penyuluhan cukup efektif dalam meningkatkan pengetahuan petani. Nilai rata-rata pengetahuan petani dalam penggunaan benih unggul padi gogo bersertifikat adalah $2419 / 30=80,06 \%$ dengan kriteria baik artinya tujuan penyuluhan yang tercantum dalam RKTP adalah agar petani mengetahui penggunaan benih unggul padi gogo bersertifikat sebesar 50\% telah tercapai.
\end{abstract}

Kata kunci: Evaluasi, Penyuluhan, Participatory rural appraisal, Benih padi gogo bersertifikat

\begin{abstract}
The purpose of this study was to evaluate the results of extention on the use of superior seeds of certified gogo rice in Nekan Village, Entikong District, Sanggau Regency. Data collection uses a participatory rural appraisal (PRA) approach to find priority issues and the dissemination of questionnaires. Questionnaire data is designed and analyzed to determine the level of knowledge of farmers towards the use of superior seeds of Certified Gogo Rice. The results showed that counseling is quite effective in improving the knowledge of farmers. The average value of farmer knowledge in the use of superior seeds of certified gogo rice is $2419 / 30=80.06 \%$ with enough criteria meaning that the purpose of counseling listed in RKTP is that farmers know the superior seeds of certified gogo rice by $50 \%$ have been achieved.
\end{abstract}

Keyword: Evaluation, Extention, Participatory rural appraisal, Gogo rice seeds certified 
Prosiding Seminar Nasional Pembangunan dan Pendidikan Vokasi Pertanian Politeknik Pembangunan Pertanian Manokwari, 14 November 2020

e ISSN : 2774-1982

\section{PENDAHULUAN}

Kecamatan Entikong merupakan pos terakhir wilayah Indonesia sebelum negara bagian Sarawak, Malaysia. Daerah ini merupakan salah satu daerah perbatasan Indoensia yang diberi fasilitas pos lintas batas negara. Sehingga interaksi antara penduduk Entikong, Malaysia, dan Brunai menjadi lumrah didaerah ini. Aktifitas bersama multinasional itu mencakupi kegiatan perdagangan, sosial, pertanian, dan sebagainya.

Penduduk Entikong mayoritas bekerja di sektor pertanian. Padi gogo dan lada perdu menjadi komoditi utama masyarakat Entikong. Data dari Badan Pusat Statistik Kabupaten Sanggau menunjukan bahwa di kecamatan Entikong terdapat 1422 hektar tanaman padi gogo dengan produksi padi se kabupaten Sanggau mencapai 25.992 ton. Sedangkan data luas pertanaman dan produksi tanaman perkebunan belum tercatat di BPS sampai sekarang. Topologi daerah yang berbukit menyebabkan lahan pertanian menyebar dan terpisah - pisah, jarang sekali kita liat sawah hamparan didaerah ini.

Situasi dan kondisi geografis tersebut menyebabkan penyuluhan pertanian menjadi sulit dilakukan. Hal ini disebabkan karena butuh waktu, biaya, dan tenaga yang besar untuk melakukan satu kali penyuluhan pertanian. Namun, masyarakat Entikong sangat antusias menyambut kegiatan penyuluhan meskipun dengan frekuensi penyuluhan yang kecil. BP3K Entikong yang menjadi penanggung jawab operasional penyuluhan pertanian di wilayah Entikong menerapkan program penyuluhan bergilir, dimana penyuluh akan melakukan penyuluhan sistem rotasi. Jika dirata-ratakan, kelompoktani akan mendapatkan penyuluhan pertanian sekali dalam sebulan dengan 4 kali penyuluhan massal perbulannya. Penyuluhan massal dilakukan dengan bantuan RRI (Radio Republik Indonesia) Entikong setiap hari Sabtu. Penyuluhan massal lebih menekankan terhadap kegiatan interaktif penyuluh hama penyakit tumbuhan dengan petani.

Keterbatasan sumber daya penyuluhan juga menjadi masalah tersendiri bagi kegiatan penyuluhan pertanian di wilayah Entikong. BP3K Entikong hanya memiliki empat orang penyuluh aktif untuk lima desa di Kecamatan Entikong, dimana dalam satu desa memiliki beberapa kelompok tani yang terpisah- pisah sangat jauh akibat isolasi geografis dan fasilitas jalan yang tidak memadai. Penelitian ini mencoba melakukan evaluasi penyuluhan terhadap pengetahuan petani dalam penggunaan benih unggul padi gogo bersertifikat. Penelitian ini ingin memberikan gambaran bagaimana progres penyuluhan di kecamatan entikong yang secara teknis belum optimal dilaksanakan karena berbagai keterbatasan.

Pengkajian evaluasi penyuluhan menghasilkan kesimpulan yang beragam, contohnya adalah penelitian yang dilakukan oleh Yuantari (2013) yang menyatakan 
Prosiding Seminar Nasional Pembangunan dan Pendidikan Vokasi Pertanian Politeknik Pembangunan Pertanian Manokwari, 14 November 2020

e ISSN : 2774-1982

bahwa tingkat pengetahuan petani sangat dipengaruhi oleh pengalaman petani, kemudian Satyani (2019) dalam penelitiannya menyatakan bahwa meskipun petani telah memiliki pengetahuan terhadap penggunaan dosis pestisida, namun kebanyakan petani masih belum sadar dalam menggunakan pestisida dengan tidak mencemari lingkungan. Kemudian Indreswari (2014) menyatakan bahwa penyuluhan sangat efektif dalam meningkatkan pengetahuan petani dalam hal manajemen pemeliharaan itik. Namun ada juga penelitian yang menyatakan bahwa penyuluhan tidak efektif dalam peningkatan pengetahuan petani sebagaimana hasil penelitian Sajow (2014) yang menunjukkan bahwa penyuluhan yang dilakukan oleh BP3K belum berhasil dan juga tidak efektif, karena kegiatan penyuluhan hanya dapat menjangkau sebagian kecil.

Dari beberapa penelitian terdahulu, disimpulkan bahwa keberhasilan penyuluhan terhadap perubahan pengetahuan petani sangat dipengaruhi oleh faktor spesifik yang ada didaerah tersebut. Kemudian, dinamika sosial disuatu daerah turut andil dalam perubahan faktor keberhasilan penyuluhan terhadap perubahan perilaku petani. Oleh karena itu, pada penelitian ini akan dijabarkan evaluasi penyuluhan terhadap tingkat pengetahuan petani dalam penggunaan benih unggul padi gogo bersertifikat yang didahului oleh pendekatan Patricipactory Rular Appraisal (PRA).

\section{METODE}

\section{Waktu dan Tempat}

Penelitian ini dilaksanakan di Desa Nekan Kecamatan Entikong Kabupaten Sanggau Provinsi Kalimantan Barat dari tanggal 1 Juli s/d 1 Agustus 2018.

\section{Teknik pengumpulan data}

\section{Data dan Jenis Data}

Sugiyono (2016) data merupakan bahan mentah yang perlu diolah untuk menghasilkan informasi atau keterangan fakta atau gambaran kondisi sehingga dapat memberi manfaat bagi peneliti, baik data kualitatif dan kuantitatif. Pada pengakajian ini data yang digunakan ialah data kuantitatif. Data kuantitatif yaitu data yang berwujud angka-angka atau bilangan. Data ini diperoleh dari pengukuran langsung maupun dari angka-angka yang diperoleh dengan mengubah data kualitatif menjadi data kuantitatif.

Penggalian data potensi wilayah diperoleh dari data, data yang digunakan dalam evaluasi penyuluhan meliputi:

1. Data primer adalah data yang diperoleh langsung dari responden dengan menggunakan kuisioner sebagai alatnya. Instrumen evaluasi berisikan tentang materi yang berhubungan dengan benih unggul padi gogo bersertifikat. Materi kuisioner disusun berhubungan dengan pengetahuan petani mencakup jenjang 
Prosiding Seminar Nasional Pembangunan dan Pendidikan Vokasi Pertanian Politeknik Pembangunan Pertanian Manokwari, 14 November 2020

e ISSN : 2774-1982

mengetahui, memahami, menggunakan pengetahuan, menganalisis unsurunsur, memadukannya dalam bentuk konsep, dan menilai pengertian.

2. Data sekunder adalah data-data yang dikumpulkan dari instansi atau lembaga terkait. Data sekunder yang dikumpulkan dalam kegiatan ini berupa data monografi kelurahan, keadaan penduduk, potensi usaha pertanian, lingkungan usaha dan kelembagaan.

Teknik pengumpulan data merupakan cara mengumpulkan data yang dibutuhkan untuk menjawab rumusan masalah penelitian. Data dikumpulkan menggunakan beberapa teknik, seperti: wawancara (interview), angket (questionnaire), pengamatan (observation) dan gabungan (triangulasi), seperti yang disampaikan oleh (Sugiyono, 2016).

\section{Instrumen Penelitian.}

Penelitian ini dilakukan untuk mengetahui tingkat pengetahuan petani mengenai benih unggul padi gogo bersertifikat. Pendekatan penelitian yang digunakan adalah pendekatan kuantitatif dan kualitatif. Metode pengumpulan data dengan menggunakan kuesioner untuk mendapatkan data kuantitatif, sedangkan untuk mendapatkan data kualitatif dilakukan observasi lapangan dan wawancara mendalam.

\section{Populasi Dan Sampel}

Populasi adalah totalitas semua nilai yang mungkin baik hasil menghitung ataupun pengukuran, kuantitatif maupun kualitatif dari karakteristik tertentu mengenai sekumpulan obyek yang lengkap dan jelas yang ingin dipelajari sifat-sifatnya (Sudjana, 2003). Populasi evaluasi penyuluhan ini adalah petani yang membudidayakan padi gogo yang terdapat di Desa Nekan Dusun Punti Tapau. Populasi diambil dari anggota dua kelompoktani yaitu Tunas Baru dan Sungai Punten yaitu 30 orang.

Sampel yang digunakan diambil dengan metoda sampling jenuh, Sugiono (2010) sampling jenuh adalah teknik penentuan sampel bila semua anggota populasi digunakan sebagai sampel. Hal ini biasa digunakan jika jumlah populasi relatif kecil, kurang dari 30 orang.

\section{Prosedur Penelitian}

Adapun prosedur kegiatan Penelitian adalah sebagai berikut:

\section{Mengidentifikasi Potensi Wilayah dan Agroekosistem}

Dalam menyiapkan penyuluhan pertanian didasari oleh potensi wilayah yang ada. Kegiatan Identifikasi Potensi Wilayah yang akan dilaksanakan adalah :

1. Mengambil dan mengumpulkan data / informasi identifikasi potensi wilayah dengan metode PRA (pelaku utama dan pelaku usaha). 
Prosiding Seminar Nasional Pembangunan dan Pendidikan Vokasi Pertanian

Politeknik Pembangunan Pertanian Manokwari, 14 November 2020

e ISSN : 2774-1982

2. Melakukan teknik PRA bersama anggota kelompok tani dalam mengambil data dengan menggunakan beberapa instrument sesuai kebutuhan yaitu peta usaha tani di kecamatan, transek, bagan kecenderungan, Diagram Venn, dan kalender musim.

3. Hasil identifikasi Potensi Wilayah disusun dalam laporan penelitian.

\section{Melaksanaan Penyuluhan}

Adapun kegiatan yang dilakukan dalam melaksanakan penyuluhan pertanian pada penelitian ini adalah :

1. Merancang penyuluhan berdasarkan materi yang sudah dipilih dengan cara menentukan metode, media,menyusun LPM dan sinopsisnya.

2. Melaksanakan penyuluhan ke kelompoktani 2 kali.

3. Menuangkan hasil pelaksanaan penyuluhan kedalam laporan penelitian

\section{Melaksanakan evaluasi penyuluhan pertanian}

Evaluasi penyuluhan bertujuan untuk mengukur tingkat keberhasilan penyuluhan terhadap perubahan perilaku petani setelah mendapatkan informasi dari penyuluhan pertanian. Penelitian ini mengkaji perubahan pengetahuan petani terhadap penggunaan benih unggul padi gogo bersertifikat

\section{Analisis data}

Analisis data bertujuan untuk mengetahui tingkat pengetahuan petani dengan menggunakan teknik skala Guttman untuk mengukur parameter pengetahuan petani. Skala guttman merupakan skala pengukuran kumulatif yang hanya mengukur satu dimensi dari suatau variabel yang multi dimensi. skala ini menghasilkan jawaban tegas “ benar - salah", "ya - tidak", "positif - negatif” dan lain-lain.

\section{HASIL DAN PEMBAHASAN}

\section{Hasil Patricipactory Rular Appraisal (PRA)}

\section{Bagan Kecenderungan dan Perubahan}

Pembuatan bagan kecenderungan dan perubahan dimaksudkan agar petani dapat mengetahui dan mengikuti perubahan di sektor pertanian sehingga dapat membuat perencanaan dan penetapan jenis usaha tani yang sesuai serta dapat berkreasi dalam menghadapi masalah yang timbul akibat perubahan tersebut

Bagan ini menjelaskan perkembangan mengenai berbagai macam jenis usaha dalam kurun waktu 5 tahun terakhir. Berikut bagan kecenderungan perubahan. 
Prosiding Seminar Nasional Pembangunan dan Pendidikan Vokasi Pertanian Politeknik Pembangunan Pertanian Manokwari, 14 November 2020

e ISSN : 2774-1982

Tabel 1. Bagan Kecenderungan dan Perubahan

\begin{tabular}{|c|c|c|c|c|c|c|}
\hline Jenis Usaha & $\begin{array}{l}\text { Tahun } \\
2013\end{array}$ & $\begin{array}{l}\text { Tahun } \\
2014\end{array}$ & $\begin{array}{l}\text { Tahun } \\
2015\end{array}$ & $\begin{array}{l}\text { Tahun } \\
2016\end{array}$ & $\begin{array}{l}\text { Tahun } \\
2017\end{array}$ & Catatan \\
\hline $\begin{array}{l}\text { Pertanian } \\
\text { Musiman }\end{array}$ & $\begin{array}{l}* * * * \\
* * * * \\
* * * *\end{array}$ & $\begin{array}{l}* * * * \\
* * * * \\
* * *\end{array}$ & $\begin{array}{c}* * * * \\
* * * * \\
* *\end{array}$ & $\begin{array}{c}* * * * \\
* * * * \\
*\end{array}$ & $\begin{array}{l}* * * * \\
* * *\end{array}$ & $\begin{array}{l}\text { Pertanian musiman } \\
\text { bergeser karena } \\
\text { perkembangan teknologi } \\
\text { pertanian dan perubahan } \\
\text { pola tanam }\end{array}$ \\
\hline $\begin{array}{c}\text { Buruh } \\
\text { Tani }\end{array}$ & $\begin{array}{l}* * * * \\
* * * *\end{array}$ & $\begin{array}{l}* * * * \\
* * *\end{array}$ & $\begin{array}{l}* * * * \\
* *\end{array}$ & $\begin{array}{c}* * * * \\
*\end{array}$ & $* * * *$ & $\begin{array}{l}\text { Buruh tani menjadi langka } \\
\text { karena bertambah peluang } \\
\text { usaha }\end{array}$ \\
\hline Dagang & $\begin{array}{l}* * * * \\
* * * *\end{array}$ & $\begin{array}{l}* * * * \\
* * * * *\end{array}$ & $\begin{array}{c}* * * * \\
* * * * \\
*\end{array}$ & $\begin{array}{l}* * * * \\
* * * * \\
*\end{array}$ & $\begin{array}{l}* * * * \\
* * * * \\
* *\end{array}$ & \\
\hline Pegawai & $* * * *$ & $* * * *$ & $* * * *$ & $* * * *$ & $* * * *$ & \\
\hline $\begin{array}{l}\text { Swasta } \\
\text { Pegawai } \\
\text { Negeri }\end{array}$ & $\begin{array}{c}* * \\
* * * *\end{array}$ & $\begin{array}{c}* * * \\
* * * * \\
*\end{array}$ & $\begin{array}{c}* * * \\
* * * * \\
* *\end{array}$ & $\begin{array}{l}* \\
* * * * \\
* * * *\end{array}$ & $\begin{array}{c}* * * * \\
* * * * \\
*\end{array}$ & $\begin{array}{l}\text { Adanya peluang menjadi } \\
\text { Pegawai Negeri }\end{array}$ \\
\hline $\begin{array}{l}\text { Wiras } \\
\text { Wasta }\end{array}$ & $* *$ & $* * * *$ & $\begin{array}{l}* * * * \\
* *\end{array}$ & $\begin{array}{l}* * * * \\
* * * * *\end{array}$ & $\begin{array}{c}* * * * \\
* * * * \\
*\end{array}$ & $\begin{array}{l}\text { Bertambahnya jenis usaha } \\
\text { memunculkan wiraswasta } \\
\text { berbagai jenis usaha }\end{array}$ \\
\hline Pendatang & $* *$ & $* * * *$ & $\begin{array}{c}* * * * \\
*\end{array}$ & $\begin{array}{l}* * * * \\
* *\end{array}$ & $\begin{array}{l}* * * * \\
* * *\end{array}$ & \\
\hline
\end{tabular}

Tabel 1 menunjukkan bahwa, bagan kecenderungan dan perubahan Desa Nekan di atas menggambarkan peningkatan kualitas hidup masyarakat desa. Ditandai dengan beberapa indikator antara lain menurunnya jumlah buruh tani dan meningkatnya jumlah pegawai. Karena letak geografis yang strategis maka jumlah pendatang dari luar kecamatan dari tahun ketahun cenderung meningkat yang berdampak pada peningkatan kebutuhan pemukiman sehingga menyebabkan laju konversi lahan pertanian menjadi pemukiman.

Perubahan-perubahan yang terjadi pada kehidupan masyarakat ada yang membawa pengaruh kearah lebih baik sebaliknya ada juga kearah yang tidak baik, oleh karena itu dengan menganalisa bagan kecendrungan dan perubahan masyarakat dapat mengatasi keadaan permasalahan dan mengantisipasi perubahan-perubahan yang akan terjadi. Akhir- akhri ini lahan di Desa Nekan mulai banyak beralih fungsi menjadi bangunan tempat tinggal. Pada tahun- tahun sebelumnya tidak menunjukkan perubahan tetapi pada tahun terakhir ada perubahan selain itu para pemuda enggan menjadi petani dan cenderung menjadi pekerja swasta dan karyawan pabrik di kota. 
Prosiding Seminar Nasional Pembangunan dan Pendidikan Vokasi Pertanian Politeknik Pembangunan Pertanian Manokwari, 14 November 2020

e ISSN : 2774-1982

\section{Kegiatan Harian Keluarga Tani}

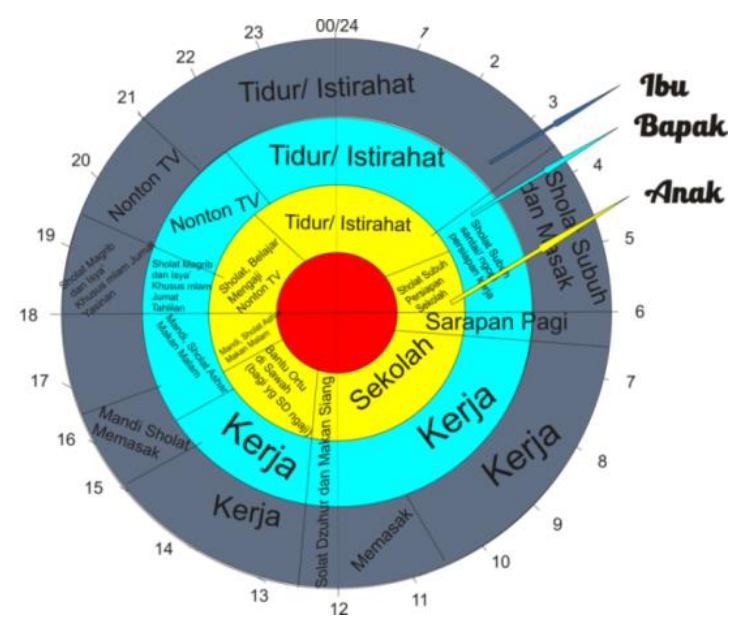

Gambar 1. Bagan kegiatan harian keluarga tani

Catatan :

a) Gambar dibuat dalam 3 buah lingkaran yang terpisah (bapak, ibu, dan anak)

b) Cara menentukan jenis kegiatan adalah dengan menjawab pertanyaan tentang kegiatan sehari-hari yang dilakukan oleh bapak, ibu dan anak.

c) Cara menentukan jam dan jumlah jam kegiatan adalah : "biasanya kegiatan tersebut dilakukan pada jam berapa?" dan "biasanya sampai jam berapa?"

d) Meskipun tidak setiap hari kegiatan yang dilakukan dan jumlah waktunya sama, ambil jenis kegiatan yang paling umum \& jumlah jam yang biasa tersedia (perkiraan saja).

e) Jadwal sehari-hari keluarga petani akan sangat bergantung pada kalender musim kegiatan pertanian : pada musim kerja kebun telah selesai, jadwal kegiatan menjadi berbeda.

\section{Bagan Hubungan Kelembagaan (Diagram Venn)}

Dalam bagan tersebut menjelaskan keadaan seberapa besar partisipasi warga dalam hubungan kelembagaan - kelembagaan yang ada di desa. Pada dasarnya seluruh lembaga yang ada di desa, berada di bawah naungan desa. Berikut bagan hubungan kelembagan (diagram Venn) 


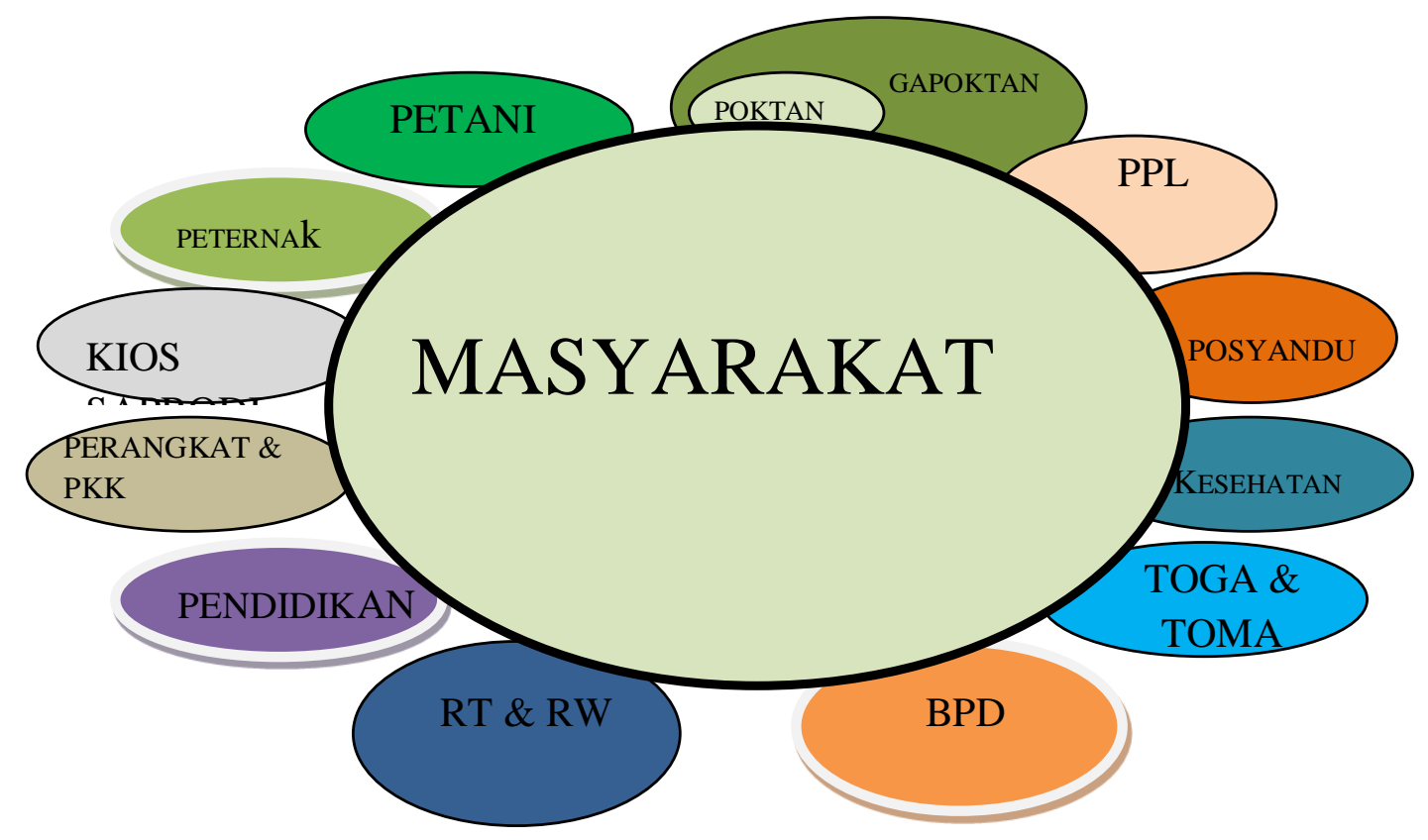

Gambar 2. Bagan Hubungan Kelembagaan (Diagram Venn)

Keterangan

TOGA DAN TOMA : Tokoh agama dan Tokoh Masyarakat

PPL

: Petugas Penyuluh Lapangan

POSYANDU : : Pos Pelayanan Terpadu

BPD : Badan permusyawa ratan Desa

Diagram venn di atas menunjukkan bahwasanya kelembagaan pertanian sangat jauh dengan masyarakat sehingga sulit untuk dijangkau. Oleh sebab itu sangat di harapkan perhatian dari pihak yang bersangkutan dengan usaha pertanian untuk menyediakan lembaga-lembaga tersebut utamanya kios saprotan agar para petani lebih mudah untuk mendapatkan pupuk dan kebutuhan usaha tani lainnya.

Pola pikir bahwa setiap pertemuan pasti membicarakan bantuan terbentuk sudah cukup lama, dan hal ini sedikit mempersulit dalam hal melakukan kegiatan PRA yaitu berkaitan dengan dana jika ingin mengumpulkan petani. Gambar tersebut menunjukkan bahwa proses perekonomian di Desa Nekan didukung juga beberapa lembaga terkait baik itu lembaga dari pemerintah dan non pemerintah yang memberikan input dalam proses perekonomian masyarakat desa Nekan.

Lembaga-lembaga tersebut memiliki peran yang sangat penting dalam memberikan informasi yang dapat mendukung atau menunjang kegiatan usaha agribisnis masyarakat tani. Keberadaan penyuluh dirasakan kurang memberikan kontribusi maksimal terhadap kehidupan masyarakat tani. Hal ini disebabkan karena tenaga penyuluh pertanian yang ada sangat terbatas. Peranan penyuluh lebih mengarah pada kepentingan program dinas dibandingkan dengan kebutuhan petani. 
Prosiding Seminar Nasional Pembangunan dan Pendidikan Vokasi Pertanian

Politeknik Pembangunan Pertanian Manokwari, 14 November 2020

e ISSN : 2774-1982

\section{Rekapan Masalah dan Potensi Desa Nekan}

Tabel 2. Hasil Patricipactory Rular Appraisal (PRA)

\begin{tabular}{|c|c|c|c|c|}
\hline Aspek & Masalah & $\begin{array}{c}\text { Faktor penyebab } \\
\text { masalah }\end{array}$ & Potensi & $\begin{array}{l}\text { Pemecahan } \\
\text { Masalah } \\
\end{array}$ \\
\hline \multirow[t]{6}{*}{$\begin{array}{l}\text { Sumber } \\
\text { daya } \\
\text { manusia }\end{array}$} & $\begin{array}{l}\text { Pemupukan yang } \\
\text { tidak berimbang } \\
\text { sesuai anjuran }\end{array}$ & $\begin{array}{l}\text { Kurangnya } \\
\text { pengetahuan, } \\
\text { keterampilan dan } \\
\text { sikap petani dalam } \\
\text { melakukan } \\
\text { pemupukan. }\end{array}$ & $\begin{array}{l}\text { PPL dan } \\
\text { Kelompok } \\
\text { Tani, BPP } \\
\text { dan Dinas } \\
\text { Pertanian. }\end{array}$ & $\begin{array}{l}\text { melakukan } \\
\text { penyuluhan } \\
\text { dan } \\
\text { demonstrasi } \\
\text { cara } \\
\text { pemupukan } \\
\text { berimbang. }\end{array}$ \\
\hline & $\begin{array}{l}\text { Kurangnya minat } \\
\text { penggunaan benih } \\
\text { unggul bersertifikat }\end{array}$ & $\begin{array}{l}\text { Mahalnya harga } \\
\text { benih sehingga sulit } \\
\text { mendapatkan dan di } \\
\text { kios saprodi tidak } \\
\text { tersedia. }\end{array}$ & $\begin{array}{l}\text { Kios saprodi } \\
\text { dan } \\
\text { POKTAN. }\end{array}$ & $\begin{array}{l}\text { Kios saprodi } \\
\text { bekerjasama } \\
\text { dengan } \\
\text { penghasil } \\
\text { benih. }\end{array}$ \\
\hline & $\begin{array}{l}\text { Budidaya ternak } \\
\text { babi yang belum } \\
\text { dikandangkan }\end{array}$ & $\begin{array}{l}\text { Masyarakat tidak } \\
\text { mau } \\
\text { mengandangkannya } \\
\text { karena kurangnya } \\
\text { pengetahuan tentang } \\
\text { budidaya babi. }\end{array}$ & $\begin{array}{l}\text { Pekarangan } \\
\text { rumah dan } \\
\text { lahan } \\
\text { kosong. }\end{array}$ & $\begin{array}{l}\text { sosialisasi } \\
\text { PPL dan } \\
\text { Dinas } \\
\text { Pertanian. }\end{array}$ \\
\hline & $\begin{array}{l}\text { Pengendalian hama } \\
\text { tanaman tidak } \\
\text { secara terpadu }\end{array}$ & $\begin{array}{l}\text { Kurangnya } \\
\text { perawatan terhadap } \\
\text { tanaman secara } \\
\text { terpadu }\end{array}$ & $\begin{array}{l}\text { Tanaman } \\
\text { sumber } \\
\text { pestisida } \\
\text { nabati dan } \\
\text { kotoran } \\
\text { ternak } \\
\text { di sekitar } \\
\text { lingkungan. }\end{array}$ & $\begin{array}{l}\text { Membuat } \\
\text { pestiida } \\
\text { nabati dan } \\
\text { kompos } \\
\text { dengan } \\
\text { pemanfaatan } \\
\text { tumbuhan } \\
\text { dan kotoran } \\
\text { ternak } \\
\text { disekitar. } \\
\text { sosialisasi } \\
\text { tentang } \\
\text { PHT. }\end{array}$ \\
\hline & $\begin{array}{l}\text { Sistem pengolahan } \\
\text { pindah tanam dan } \\
\text { membakar lahan } \\
\text { membuat lahan } \\
\text { kurang kandungan } \\
\text { organik. }\end{array}$ & $\begin{array}{l}\text { Masih banyaknya } \\
\text { lahan kosong dan } \\
\text { kebiasaan petani } \\
\text { membakar. }\end{array}$ & $\begin{array}{l}\text { Penggunaan } \\
\text { sisa } \\
\text { tumbuhan } \\
\text { sebagai } \\
\text { kompos. }\end{array}$ & \\
\hline & $\begin{array}{l}\text { Kurangnya minat } \\
\text { dan motivasi petani } \\
\text { dalam pemeliharaan } \\
\text { tanaman sehingga } \\
\text { petani masih } \\
\text { menerapkan sistem } \\
\text { pertanian } \\
\text { konvensional. }\end{array}$ & $\begin{array}{l}\text { Kurangnya sosialisai } \\
\text { penyuluahan } \\
\text { kepetani dalam } \\
\text { teknologi pertanian. }\end{array}$ & $\begin{array}{l}\text { PPL, BPP } \\
\text { dan Dinas } \\
\text { Pertanian. }\end{array}$ & $\begin{array}{l}\text { Melakukan } \\
\text { sosialisai } \\
\text { penyuluahan } \\
\text { kepetani } \\
\text { dalam } \\
\text { teknologi } \\
\text { pertanian. }\end{array}$ \\
\hline
\end{tabular}


Prosiding Seminar Nasional Pembangunan dan Pendidikan Vokasi Pertanian Politeknik Pembangunan Pertanian Manokwari, 14 November 2020

e ISSN : 2774-1982

\begin{tabular}{llll}
\hline $\begin{array}{l}\text { Pengetahuan petani } \\
\text { dalam teknologi } \\
\text { pembibitan lada } \\
\text { masih rendah. }\end{array}$ & $\begin{array}{l}\text { Belum adanya } \\
\text { sosialisai mengenai } \\
\text { pembibitan. }\end{array}$ & $\begin{array}{l}\text { PPL, BPP } \\
\text { dan Dinas } \\
\text { Pertanian. }\end{array}$ & $\begin{array}{l}\text { Melakukan } \\
\text { demcar } \\
\text { pembbitan } \\
\text { lada perdu } \\
\text { dan panjat. }\end{array}$ \\
$\begin{array}{l}\text { Tidak adanya } \\
\text { pemberian bahan } \\
\text { organik terhadap } \\
\text { tanah dan tanaman } \\
\text { sehingga } \\
\text { produktivitas } \\
\text { tanaman rendah. }\end{array}$ & $\begin{array}{l}\text { Petani tidak tahu } \\
\text { manfaat pupuk } \\
\text { organik dan cara } \\
\text { pembuatannya. }\end{array}$ & $\begin{array}{l}\text { PPL, BPP } \\
\text { dan Dinas } \\
\text { Pertanian. }\end{array}$ & $\begin{array}{l}\text { Pemcar } \\
\text { Pembuatan } \\
\text { pupuk } \\
\text { organik. }\end{array}$ \\
& & & \\
\hline
\end{tabular}

Sumber : Monografi Desa Nekan 2017

Tabel 2 menjelaskan hasil pengamatan dari lapangan bahwa dalam memecahkan masalah yang dihadapi petani masih banyak potensi yang akan dimanfaatkan. Masyarakat desa mempunyai pendidikan rendah sehingga membutuhkan banyak sosialisasi dan demonstrasi langsung dilapangan. Dengan kegiatan tersebut diharapkan pengetahuan petani meningkat sehingga mempunyai sumberdaya manusia yang terampil dan bersinergitas dalam bidang pertanian. Terampilnya petani dapat meningkatkan hasil produksi dan produktivitas yang tinggi sehingga tingkat kesejahteraan petani meningkat.

Permasalahan dari segi kelembagaan sistem dan usaha agribisnis serta sarana dan prasarana yakni masih rendahnya kesadaran petani dalam Pembentukan koperasi dan asosiasi sementara poktan dan gapoktan sebagai potensi untuk mendirikannya. Diharapkan penyuluh, BPP dan Dinas Pertanian lebih memperhatikan rantai pemasaran petani agar mereka mau memperpendek jalur distribusi pemasaran dengan membuat asosiasi petani karena mempunyai komoditi unggulan lada dan padi gogo.

\section{Evaluasi penyuluhan pertanian}

\section{Karakteristik Internal Petani}

Karakteristik petani merupakan salah satu faktor yang perlu diperhatikan oleh pemerintah daerah dalam meningkatkan pengetahuan petani. Untuk meningkatkan kualitas karakteristik petani dapat dilakukan dengan melakukan penyuluhan pertanian secara berkala dan berkelanjutan melalui program penyuluhan yang melibatkan petani dan potensi sumberdaya alam yang spesifik lokasi. Adapun karakteristik petani yang menjadi faktor-faktor mempengaruhi pengetahuan dalam evaluasi penyuluhan ini adalah sebagai berikut. 
Prosiding Seminar Nasional Pembangunan dan Pendidikan Vokasi Pertanian Politeknik Pembangunan Pertanian Manokwari, 14 November 2020

e ISSN : 2774-1982

\section{Umur}

Berdasarkan hasil wawancara yang dilakukan terhadap 30 petani responden tingkat umur petani responden dapat disajikan pada tabel 3 .

Tabel 3. Rekapitulasi Tingkat Umur Petani Responden.

\begin{tabular}{ccc}
\hline Umur & Jumlah (orang) & $\begin{array}{c}\text { Persentase } \\
(\%)\end{array}$ \\
\hline $\mathbf{3 0}-\mathbf{3 5}$ & 6 & $\mathbf{2 0 , 0}$ \\
$\mathbf{3 6}-\mathbf{4 0}$ & 10 & $\mathbf{3 3 , 3}$ \\
$\mathbf{4 1}-\mathbf{4 5}$ & 8 & $\mathbf{2 6 , 6}$ \\
$\mathbf{4 6}-\mathbf{5 0}$ & 6 & $\mathbf{2 0 , 0}$ \\
\hline Jumlah & 30 & 100 \\
\hline Sumber : Data primer diolah & &
\end{tabular}

Tabel 3 menunjukan bahwa sebagian responden berada pada tingkatan umur 30 50 tahun 30 petani $(100 \%)$ yang artinya responden termasuk dalam kategori umur produktif dan jika dihubungkan dengan adopsi maka responden termasuk petani yang cepat dalam menerapkan suatu inovasi.

$$
\begin{aligned}
& =\frac{6+10+8+6}{30} \times 100 \% \\
& =\frac{30}{30} \times 100 \% \\
& =\frac{3000}{30} \% \\
& =100 \%
\end{aligned}
$$

Seperti diungkapkan oleh Soekartawi, (1988) bahwa makin muda umur penduduk biasanya mempunyai rasa ingin tahu yang tinggi dan berusaha untuk lebih cepat melakukannya walaupun belum berpengalaman. Dan semakin tua (diatas 50 tahun) biasanya semakin lamban menerapkan inovasi dan cenderung hanya melaksanakan kegiatan yang sudah biasa dilakukan masyarakat setempat Lionberger, (1960) dalam (Mardikanto,T, 2009)

\section{Tingkat pendidikan}

Tingginya anak putus sekolah dan rendahnya kualitas sumberdaya manusia merupakan permasalahan utama di bidang pendidikan. Sumberdaya manusia yang ada pada pengembangan sektor pertanian dan sektor lainnya rendah akibat rendahnya tingkat pendidikan penduduk. Adapun jumlah responden yang mengikuti pendidikan mulai dari sekolah dasar sampai perguruan tinggi disajikan pada tabel 4 
Prosiding Seminar Nasional Pembangunan dan Pendidikan Vokasi Pertanian Politeknik Pembangunan Pertanian Manokwari, 14 November 2020

e ISSN : 2774-1982

Tabel 4. Rekapitulasi Tingkat Pendidikan Formal Petani Responden

\begin{tabular}{lcc}
\hline \multicolumn{1}{c}{ Pendidikan Formal } & Jumlah (orang) & Persentase (\%) \\
\hline SD & 20 & $\mathbf{6 6 , 7}$ \\
SLTP & 8 & $\mathbf{2 6 , 7}$ \\
SLTA & 0 & $\mathbf{0}$ \\
Perguruan Tinggi & 2 & $\mathbf{6 , 7}$ \\
\hline Jumlah & 30 & 100 \\
\hline
\end{tabular}

Sumber : Data primer diolah

Tabel 4 menunjukan bahwa tingkat pendidikan petani responden dominannya adalah tamat SD berjumlah 20 orang $(66,7 \%)$ dan SLTP berjumlah 8 orang $(26,7 \%)$, dan perguruan tinggi berjumlah 2 orang $(6,7 \%)$. Hal ini menunjukkan responden belum menganggap penting arti pendidikan formal. Tingkat pendidikan responden akan mempengaruhi penerimaan mereka terhadap hal-hal baru, terutama dalam menggunakan benih unggul padi gogo bersertifikat. Tingkat pendidikan tamatan SLTP dan SLTA ini, diharapkan petani dapat semakin terbuka terhadap segala teknologi baru yang ada disekitar. Hal ini sejalan dengan pendapat Totok Mardikanto (1993) bahwa pendidikan adalah proses pengembangan pengetahuan maupun sikap seseorang yang dilakukan secara terencana, yang akan membentuk wawasan terhadap suatu objek yang akhirnya akan mengarahkan pada pengambilan keputusan.

\section{Jumlah Menurut Jenis Kelamin.}

Jenis kelamin menunjukkan kemampuan fisik dalam berusahatani. Selain itu, jenis kelamin juga berpengaruh terhadap kemampuan memimpin dan mengambil keputusan dalam berbagai kegiatan termasuk dalam kegiatan usahatani. Jenis kelamin responden pada evaluasi penyuluhan pertanian ini tertera pada tabel 5 .

Tabel 5. Rekapitulasi Jumlah Responden Berdasarkan Jenis Kelamin

\begin{tabular}{llll}
\hline No & Jenis kelamin & Jumlah orang & Persentase \% \\
\hline $\mathbf{1}$ & Laki-laki & 30 & $\mathbf{1 0 0}$ \\
\hline Jumlah & & 30 & 100 \\
\hline
\end{tabular}

Sumber : Data primer diolah

Tabel 5 menunjukkan bahwa, responden dalam evaluasi ini semuanya adalah lakilaki. Hal ini menunjukkan bahwa kaum laki-laki lebih banyak berperan dalam menerapkan inovasi baru dalam usahatani. Hal tersebut dapat terjadi karena memang dalam pengolahan lahan, penanaman, perawatan serta panen lebih banyak peranan lakilaki karena kekuatan fisiknya lebih bisa diandalkan dibanding perempuan. 
Prosiding Seminar Nasional Pembangunan dan Pendidikan Vokasi Pertanian Politeknik Pembangunan Pertanian Manokwari, 14 November 2020

e ISSN : 2774-1982

\section{Luas Lahan Yang Diusahakan.}

Luas lahan garapan petani responden dapat dipengaruhi oleh produktivitas petani itu sendiri. Semakin luas lahan garapan semakin besar peluang dalam memproduksi hasil pertanian. Data produksi luas lahan disajikan pada tabel 6.

Tabel 6. Luas Garapan Petani Responden

\begin{tabular}{lcc}
\hline Luas Garapan (Ha) & Jumlah (orang) & Persentase (\%) \\
\hline $\mathbf{0 , 2 5}-\mathbf{0 , 5 0}$ & 23 & $\mathbf{7 5 , 3}$ \\
$\mathbf{0 , 5 1}-\mathbf{1}$ & 7 & $\mathbf{2 3 , 3}$ \\
\hline Jumlah & 30 & 100 \\
\hline
\end{tabular}

Sumber : Data primer diolah

Tabel 6 menjelaskan bahwa, luas lahan petani responden dengan luas lahan 0,25 0,50 ha sebanyak 23 orang (75.3\%), dan lahan $0,51-1$ ha sebanyak 7 orang (23,3\%). Luas lahan berpengaruh terhadap adopsi petani dalam meneriman inovasi baru sebagaimana yang disampaikan oleh Mardikanto, (2009) bahwa semakin luas usahatani biasanya semakin cepat meningkatkan penghasilannya, karena memiliki kemampuan ekonomi yang lebih baik.

\section{Pengetahuan Petani tentang benih unggul padi gogo bersertifikat.}

Penyuluhan pertanian telah dilaksanakan dengan materi penyuluhan yaitu benih unggul padi gogo bersertifikat dengan tujuan penyuluhan adalah petani menggunakan benih unggul padi gogo bersertifikat sebesar 50\%. Adapun tujuan dilaksanakannya evaluasi penyuluhan pertanian adalah untuk mengetahui nilai rata-rata pengetahuan petani dan persentase peningkatan penguasaan pengetahuan tentang benih unggul padi gogo bersertifikat. Menurut Arikunto (2013) hasil ukur pengetahuan dapat dikelompokkan menjadi 3 kategori yaitu : Baik (76\%-100\%), Cukup ( 56\%-75\%), Kurang (<55). Untuk mengetahui nilai rata-rata pengetahuan benih unggul padi gogo bersertifikat ada pada tabel 7:

Tabel 7. Rekapitulasi Nilai Kuisioner Rata-Rata Pengetahuan Petani

\begin{tabular}{llcccc}
\hline No & \multicolumn{1}{c}{$\begin{array}{c}\text { Nama Petani } \\
\text { Responden }\end{array}$} & \multicolumn{2}{c}{ Jawaban } & $\begin{array}{c}\text { Nilai } \\
\text { Responden }\end{array}$ & Skala \\
\cline { 3 - 4 } $\mathbf{1}$ & Suyono & Benar & Salah & \\
$\mathbf{2}$ & Jaka & 13 & 2 & 86 & B \\
$\mathbf{3}$ & Sumaryono & 12 & 3 & 80 & B \\
$\mathbf{4}$ & Sayan & 11 & 5 & 66 & $\mathrm{C}$ \\
$\mathbf{5}$ & Bejik & 9 & 4 & 73 & $\mathrm{C}$ \\
$\mathbf{6}$ & Pendi & 12 & 6 & 60 & $\mathrm{C}$ \\
$\mathbf{7}$ & Abeng & 11 & 3 & 80 & B \\
$\mathbf{8}$ & Linggek & 5 & 10 & 73 & $\mathrm{C}$ \\
$\mathbf{9}$ & Aron & 10 & 5 & 33 & $\mathrm{~K}$ \\
\hline
\end{tabular}


Prosiding Seminar Nasional Pembangunan dan Pendidikan Vokasi Pertanian Politeknik Pembangunan Pertanian Manokwari, 14 November 2020

e ISSN : 2774-1982

\begin{tabular}{|c|c|c|c|c|c|}
\hline 10 & Lasdi & 11 & 4 & 73 & $\bar{C}$ \\
\hline 11 & Kantina & 6 & 9 & 40 & $\mathrm{~K}$ \\
\hline 12 & Jolami & 12 & 3 & 80 & B \\
\hline 13 & Tangkok & 12 & 3 & 80 & B \\
\hline 14 & Mangko & 13 & 2 & 86 & B \\
\hline 15 & Emanuel Kadol & 11 & 4 & 73 & $\mathrm{C}$ \\
\hline 16 & Tom Sujarwo & 15 & 0 & 100 & A \\
\hline 17 & Nyamping & 15 & 0 & 100 & A \\
\hline 18 & Sayang & 14 & 1 & 90 & A \\
\hline 19 & Ridet & 14 & 1 & 90 & A \\
\hline 20 & Pendi & 9 & 6 & 60 & $\mathrm{C}$ \\
\hline 21 & Nuel & 11 & 4 & 70 & $\mathrm{C}$ \\
\hline 22 & Diben & 15 & 0 & 100 & A \\
\hline 23 & Jabol & 8 & 2 & 80 & $\mathrm{~B}$ \\
\hline 24 & Yono & 15 & 0 & 100 & A \\
\hline 25 & Darmadi & 15 & 0 & 100 & A \\
\hline 26 & Bambang & 15 & 0 & 100 & A \\
\hline 27 & Liyam & 12 & 3 & 80 & B \\
\hline 28 & Jaka & 15 & 0 & 100 & A \\
\hline 29 & Tobing & 15 & 0 & 100 & A \\
\hline 30 & Obito & 15 & 0 & 100 & A \\
\hline \multicolumn{3}{|c|}{ Jumlah nilai responden } & & 2.419 & \\
\hline \multicolumn{2}{|c|}{ Rata- rata } & \multicolumn{2}{|c|}{12.03} & 80,6 & \\
\hline
\end{tabular}

Sumber : Data primer diolah

Tabel 7 menjelaskan nilai rata-rata pengetahuan petani dalam penggunaan benih unggul padi gogo bersertifikat sebesar adalah $2.419 / 30=80,06 \%$ dengan kriteria baik. Artinya tujuan penyuluhan yang tertera di RKTP yaitu petani mengetahui benih unggul padi gogo bersertifikat sebesar 50\% sudah tercapai. Hal ini karena nilai yang melebihi dari tujuan yaitu $80,06 \%$. Hasil evaluasi tersebut dipengaruhi tingkat pendidikan formal yang rendah sehingga wawasan petani cukup dalam teknologi pertanian. Walaupun tidak sesuai dengan pendapat Mardikanto (1993) bahwa pendidikan tinggi akan Berhubungan dengan tingkat pengetahuan dan keterampilan petani, dimana petani akan berusaha untuk memanfaatkan setiap kesempatan yang dapat memajukan usahataninya. Namun, meskipun petani di desa Nekan rata - rata memiliki pendidikan rendah, tapi petani sangat antusias dalam meyambut kegiatan penyuluhan pertanian. Sehingga petani lebih responsif terhadap adopsi teknologi. Selain itu, tercapainya tingkat pengetahuan tersebut, karena sering adanya kegiatan anjangsana dan penyuluhan di Desa Nekan, khususnya di Kelompok tani Tunas baru dan sungai punten dusun punti tapau dengan berbagai materi penyuluhan yang dibutukan petani.

Persentase tingkat pengetahuan petani terhadap benih unggul padi gogo bersertifikat diukur melalui jawaban pada kuesioner yang telah dibagi pada petani. Persentase nilai pengetahuan petani melalui pretest dan postest disajikan pada Tabel 8 . 
Prosiding Seminar Nasional Pembangunan dan Pendidikan Vokasi Pertanian Politeknik Pembangunan Pertanian Manokwari, 14 November 2020

e ISSN : 2774-1982

Tabel 8. Rekapitulasi nilai tingkat pengetahuan petani

\begin{tabular}{|c|c|c|c|}
\hline No & Nama Responden & Nilai Pretest & Nilai Postest \\
\hline $\mathbf{1}$ & Suyono & 9 & 13 \\
\hline 2 & Jaka & 10 & 12 \\
\hline 3 & Sumaryono & 7 & 10 \\
\hline 4 & Sayan & 7 & 11 \\
\hline 5 & Bejik & 5 & 9 \\
\hline 6 & Pendi & 8 & 12 \\
\hline 7 & Abeng & 9 & 11 \\
\hline 8 & Linggek & 2 & 5 \\
\hline 9 & Aron & 5 & 10 \\
\hline 10 & Lasdi & 6 & 11 \\
\hline 11 & Kantina & 2 & 6 \\
\hline 12 & Jolami & 10 & 12 \\
\hline 13 & Tangkok & 5 & 12 \\
\hline 14 & Mangko & 11 & 13 \\
\hline 15 & Emanuel Kadol & 8 & 11 \\
\hline 16 & Tom Sujarwo & 11 & 15 \\
\hline 17 & Nyamping & 12 & 15 \\
\hline 18 & Sayang & 10 & 14 \\
\hline 19 & Ridet & 7 & 14 \\
\hline 20 & Pendi & 8 & 9 \\
\hline 21 & Nuel & 7 & 11 \\
\hline 22 & Diben & 8 & 15 \\
\hline 23 & Jabol & 7 & 8 \\
\hline 24 & Yono & 9 & 15 \\
\hline 25 & Darmadi & 11 & 15 \\
\hline 26 & Bambang & 6 & 15 \\
\hline 27 & Liyam & 11 & 12 \\
\hline 28 & Jaka & 6 & 15 \\
\hline 29 & Tobing & 8 & 15 \\
\hline \multirow[t]{5}{*}{30} & Obito & 12 & 15 \\
\hline & Jumlah & 237 & 361 \\
\hline & Nilai rata-rata pretest & $237: 30=7.9$ & \\
\hline & Nilai rata-rata postest & $361: 30=12,03$ & \\
\hline & Selisih nilai peningkatan & $12,03-7.9=4.13$ & \\
\hline
\end{tabular}

Sumber : Data primer diolah

Tabel 8 menunjukkan persentase peningkatan pengetahuan petani Dusun Punti Meraga dan Punti Tapau terhadap benih unggul padi gogo bersertifikat yaitu :

$\%$ Peningkatan Pengetahuan Petani $=\frac{\text { Selisih nilai } \text { responden }}{\text { Nilai pretest responden }} \times 100 \%$

$$
\begin{aligned}
& =\frac{361-237}{237} \times 100 \% \\
& =\frac{124}{237} \times 100 \% \\
& =52 \%
\end{aligned}
$$


Prosiding Seminar Nasional Pembangunan dan Pendidikan Vokasi Pertanian Politeknik Pembangunan Pertanian Manokwari, 14 November 2020

e ISSN : 2774-1982

Persentase peningkatan terlihat bahwa persentase pengetahuan petani responden tentang benih unggul padi gogo bersertifikat sebesar 52\%. Jika dilihat melalui garis kontinum sebagai berikut:

$\begin{array}{llllll}0 \% & 20 \% & 40 \% & 60 \% & 80 \% & 100 \%\end{array}$

\begin{tabular}{|l|l|l|l|l|} 
Sangat rendah & rendah & Sedang & Tinggi & sangat tinggi \\
\hline & $52 \%$ & &
\end{tabular}

Gambar 2. Garis Kontinum pengetahuan petani benih unggul padi gogo bersertifikat.

Berdasarkan garis kontinum tersebut dapat dilihat bahwa petani responden di Dusun Punti Tapau dan Punti Meraga memiliki tingkat perubahan pengetahuan berada pada kategori sedang atau cukup paham tentang benih unggul padi gogo bersertifikat yang disampaikan oleh penyuluh kepada petani. Hal ini berarti tujuan penyuluhan pertanian agar petani mau menggunakan benih unggul padi gogo bersertifikat dari $20 \%$ menjadi 50\% telah tercapai. Selain itu, dengan beberapa penekanan yang dilakukan penyuluh pada materi penyuluhan terutama tentang manfaat jangka panjang penggunaan benih unggul padi gogo bersertifikat. Petani menjadi tertarik dan termotivasi untuk menggunakannya pada pertanaman selanjutnya.

\section{KESIMPULAN DAN SARAN}

\section{Kesimpulan}

Dari hasil evaluasi penyuluhan terhadap pengetahuan petani dalam penggunaan benih unggul padi gogo bersertifikat maka dapat disimpulkan sebagai berikut:

1. Potensi yang terdapat di Desa Nekan ( SDM, SDA dan Lingkungan) sangat mendukung dalam berusahatani, permasalahan yang dihadapi juga termasuk pada skala mudah karena wilayah ini masih banyak memiliki potensi yang belum dikembangkan dengan optimal

2. Peningkatan pengetahuan petani responden tentang benih unggul padi gogo bersertifikat dengan nilai rata-rata pengetahuan petani sebesar adalah $2.419 / 30=$ $80,06 \%$ dengan kriteria baik. Artinya tujuan penyuluhan yang tertera di RKTP yaitu petani mengetahui benih unggul padi gogo bersertifikat sebesar 50\% sudah tercapai. Hal ini karena nilai yang melebihi dari tujuan yaitu $80,06 \%$. 
Prosiding Seminar Nasional Pembangunan dan Pendidikan Vokasi Pertanian

Politeknik Pembangunan Pertanian Manokwari, 14 November 2020

e ISSN : 2774-1982

3. Berdasarkan garis kontinum dapat dilihat bahwa perubahan pengetahuan petani tehadap penyuluhan sebesar $52 \%$ dengan kategori sedang.

\section{Saran}

1. Sebaiknya penyuluh dilapangan setiap tahunnya membuat pemeringkatan masalah yang dihadapi dilapangan pada potensi usahatani yaitu padi gogo, Jagung, Kacang tanah, Karet, lada dan kelapa sawit sesuai dengan keadaan dilapangan sehingga permasalahan dapat diprioritaskan dan dikendalikan.

2. Penyuluh seharusnya membuat Programa Penyuluhan Pertanian sesuai dengan permentan nomor 47 tahun 2016.

3. Penyusunan RKTP sebaiknya berpedoman dari programa desa yang telah dibuat.

4. Penyuluh pertanian dalam menyiapkan penyuluhan sebaiknya dahulu melakukan identifikasi, membuat programa dan RKTP.

\section{DAFTAR PUSTAKA}

Indeswati, S. (2014). Evaluasi Penyuluhan Pemeliharaan Itik Lokal Jantan Berbasis Metode Inditik Terhadap Tingkat Pengetahuan dan Sikap Petani Di Desa Gaum, Kecamatan Tasikmadu, Kabupaten Karanganyar. Sains Peternakan Vol. 12 (1), Maret 2014: 56-60 ISSN 1693-8828

Mardikanto, T. (2009). Sistem Penyuluhan Pertanian. UNS Press. Surakarta.

Mardikanto \& Soebiato. (2013). Pemberdayaan Masyarakat Dalam Prespektif Kebijakan Publik. Bandung: Alfabeta.

Nasution, Z. (1990). Prinsip Prinsip Komunikasi Untuk Penyuluhan. Lembaga Penerbit Fakultas Ekonomi Universitas Indonesia. Jakarta.

Nurhidayati, dkk. (2008). E-Book Pertanian Organik. Malang. Program Studi Agroteknologi, Jurusan Budidaya Pertanian, Fakultas Pertanian Universitas Islam Malang. 196 Hal.

Ridwan. (2020). Dasar-Dasar Statistika/ Bandung: Alfabeta.

Sajow, Nissa. (2014). Evaluasi Program Penyuluhan Usaha Peternakan Sapi Di Kecamatan Sinonsayang Kabupaten Minahasa Selatan. Jurnal Zootek ("Zootrek" Journal) Vol 34 No. 2 : 27-38 (Juli 2014)

Satyani, Tri. (2019). Evaluasi Penggunaan Pestisida Pada Petani Bawang Merah Di Desa Wombo Mpanau Kecamatan Tanantovea Kabupaten Donggala. Jurnal aggrotech 9 (1) $26-32$

Suwandi, A. (2006). Diktat: Implementasi Participatory Rural Appraisal (PRA). Sekolah Tinggi Penyuluhan Pertanian Bogor : Bogor.

Sujarweni. (2014). SPSS untuk Penelitian. Yogyakarta: Pustaka Baru Press 
Prosiding Seminar Nasional Pembangunan dan Pendidikan Vokasi Pertanian

Politeknik Pembangunan Pertanian Manokwari, 14 November 2020

e ISSN : 2774-1982

Sugiyono. (2016). Metode Penelitian Kuantitatif, Kualitatif dan $R \& D$. Bandung: Alfabeta

Sugiyono. (2014). Metode Penelitian Kuantitatif, Kualitatif dan $R \& D$. Bandung: Alfabeta

Undang-Undang Republik Indonesia No. 16 Tahun 2006.Tentang Sistem Penyuluhan Pertanian, Perikanan dan Kelautan

Van Den ban, A.W \& Hawkins, H.S. (1999). Penyuluh Pertanian. Kanisius. Jogjakarta.

Wijiyanto, Agus. (2015). Teori Relevansi; Komunikasi dan Kognisi. Jurnal Metalingua, Vol. 13 No. 1

Yuantari, MG Catur. (2013). Tingkat Pengetahuan Petani dalam Menggunakan Pestisida (Studi Kasus di Desa Curut Kecamatan Penawangan Kabupaten Grobogan). Prosiding Seminar Nasional Pengelolaan Sumberdaya Alam dan Lingkungan 2013. 